\title{
Soft isostasy in geomorphology
}

\author{
Mohsen Pourkhosravani ${ }^{a}$, Mohammad Hosain Ramesht ${ }^{a^{*}}$, Seyed Ali Almodaresi ${ }^{\text {b }}$, Seyed Ebrahim \\ Hosseini Ebrahim Abadi and Tayebeh Mohammadi Mohammad Abadi
}

${ }^{a}$ Department of Geography, Isfehan University, Esfehan, Iran

${ }^{b}$ Department of Civil Engineering, Islamic Azad University, Yazd branch, Yazd, Iran

\begin{tabular}{l}
\hline A R T I C L E I N F O \\
\hline Article history: \\
Received May 25, 2011 \\
Received in Revised form \\
September, 4, 2011 \\
Accepted 5 September 2011 \\
Available online \\
8 September 2011 \\
\hline Keywords: \\
Earth subsidence \\
Geomorphology \\
Soft isostasy \\
Tectonic movements
\end{tabular}

Tectonic movements

\section{A B S T R A C T}

\begin{abstract}
Earth subsidence has been one of the important issues jeopardizing environment and there are many studies, which blame shortage of underground water resources for having uplift and subsidence. However, many argue such conclusion and believe that earth subsidence has been studied in the past without considering the changes in the hill over a long period. In this study, we use SAR interferometry study to investigate earth subsidence in dessert areas of Esfahan, Yazd and Ardakan, located in central part of Iran. The results indicate that there are more important issues affecting subsidence such as the uplift in the hills located the desert area. The results of the survey based on SAR interferometry reveals that subsidence occurs with the uplift in the adjacent hills, simultaneously called Soft isostasy in geomorphology. In other words, the subsidence is more associated with the movement of the surface of the desert to reach equilibrium than shortage of underground water resources. There is an equilibrium line between the uplift and subsidence where is changes of the surface tends to zero.
\end{abstract}

(C) 2012 Growing Science Ltd. All rights reserved.

\section{Introduction}

Earth subsidence has become one of the most important studies among geomorphologies. There are different theories to explain the reasons behind the earth subsidence such as the shortage of underground water resources, emerge of lava from underground, mining operations, melting the ices, oil refinery operations, etc. The primary outcome of all these operations is to see a number of cracks on the surface of lands. During the past few three decades, there have been tremendous operations for using underground water resources. Many people believe that these operations are important reasons for having so many cracks in the lands in Iran. During the past two decades, the weather condition in Iran has been dry; there were shortage of water resources and there has been an increase on using underground water resources. However, there have been many arguments that there is not a strong scientific proof to blame shortage of water resources as the only reason for such incidents. During the past few years, there have been different attempts to investigate such incidents (Jonathan, 2001, Gutiérrez, 2004).

* Corresponding author. Tel: +09131160245

E-mail addresses: mramesht@yahoo.com (M. H. Ramesht) 
Heidari et al. (2011) reported that most sinkholes in the Hamedan region central plain in western Iran are developed in partially unconsolidated sediments overlying Oligo-Miocene limestone. They performed a detailed analyses of hydrologic and hydrogeologic conditions from 1988 to 2008 and reported that conditions were favorable for sinkhole development. These sinkholes developed in groundwater discharge areas near the base of karstic Oligo-Miocene limestone in zones with major groundwater circulation, thick overburden and a close proximity to deep-source carbon dioxide gas. According to Heidari et al. (2011) high carbon dioxide partial pressures, created by rising gases from pneumatolytic and hydrothermal phase sources, renew the aggressiveness of the water in the vicinity of the discharge zone. The acidic water dissolves limestone, especially along the fractures and joints. Moreover, the presence of large conduits below the surface allows for the transport of unconsolidated sediments and the continual development of sinkholes.

Stecchi et al. (2009) performed a curvature analysis as a tool for subsidence-related risk zones identification in the city of Tuzla. They claimed that the massive extraction activities had led to severe subsidence accommodated by collapse and strain localization. They analyzed the salt dissolution-related morphological development of the Tuzla topography to identify the location of faults and fractures in the deformed area. They also implemented curvature analysis to the subsidence surface using two different analytical methods of the directional as well as two-dimensional curvature and the analytic Gaussian curvature. The comparison of the curvature maps with those of surface fractures visible in the area reported that a good spatial agreement between the directional curvature and fracture intensity, whereas the subsurface normal faults were more evident in the Gaussian curvature maps.

Keller et al. (2007) investigated the geomorphology of the western sector of the Mid-Channel Anticline (MCA), Santa Barbara, Southern California and reported that the actively growing fold is laterally propagating to the west. The presence of fold scarps and cross faults that segment the structure recommends that buried faults, which are producing the folding are present at shallow depths. According to their studies, evidence for presence of the island indicates terrestrial erosion and the assumption of sea level change and rates of uplift and subsidence. Guccione et al. (2001) studied stream response to repeated coseismic folding, Tiptonville dome, New Madrid seismic zone. Malik and Mohanty (2002) studied active tectonic influence on the evolution of drainage and landscape geomorphic signatures from frontal and hinter land areas along the North western Himalya, India.

In this paper, we present an empirical study to use SAR interferometry study to investigate earth subsidence in dessert areas of Esfahan, Yazd and Ardakan, located in central part of Iran. The orientation of this paper, first explains the necessary tools implemented for this research in section 2 and details of our computations are given in section 3. Finally, concluding remarks are given in the last to summarize the contribution of this paper.

\section{The proposed study}

The proposed study of this work use Syenthetic aperture radar to measure the changes in the surface.

\subsection{Synthetic aperture radar (SAR)}

Synthetic aperture radar (SAR) is a kind of radar in which sophisticated processing of radar data is implemented to generate a very narrow effective beam by moving tools over relatively immobile targets (Goldstein et al., 1993; Massonnet et al., 1993; Massonnet et al., 1995). SAR is a form of active remote sensing where an antenna transmits radiation, which is reflected from the target, as opposed to passive sensing, and the reflection is detected from ambient illumination. The image acquisition is therefore does not depend on the natural illumination and images can be taken at night. Radar gathers electromagnetic radiation with microwave frequencies; the atmospheric absorption at 
typical radar wavelengths is very low, meaning observations are not prevented by cloud cover. Most SAR applications take advantage of the amplitude of the return signal, and ignore the phase data. However, interferometry applies the phase of the reflected radiation. Since the outgoing wave is generated by the satellite, the phase is known, and can be compared to the phase of the return signal. The phase of the return wave is a function of the distance to the ground, since the path length to the ground and back consists of a number of whole wavelengths plus some fraction of a wavelength. The total number of whole wavelengths is not known, but the extra fraction of a wavelength can be measured very accurately. SAR interferometry is one of useful techniques to measure the changes in the earth's surface (Massonnet \& Feigl, 1998).

\subsection{The region of the proposed study}

\subsubsection{North Mahyar desert}

Mahyar desert is located 25 kilometers south of city of Esfahan, Iran. The region is cover with calcareous rocks of cretaceous and there are many Rocky Mountains. Many sediment erosions cover the areas of desert and there are various faults.

\subsubsection{Yazd-Ardakan region}

This region is located in central part of Yazd and it contains many well-known faults. Fig. 1 shows geographical specifications of the region.

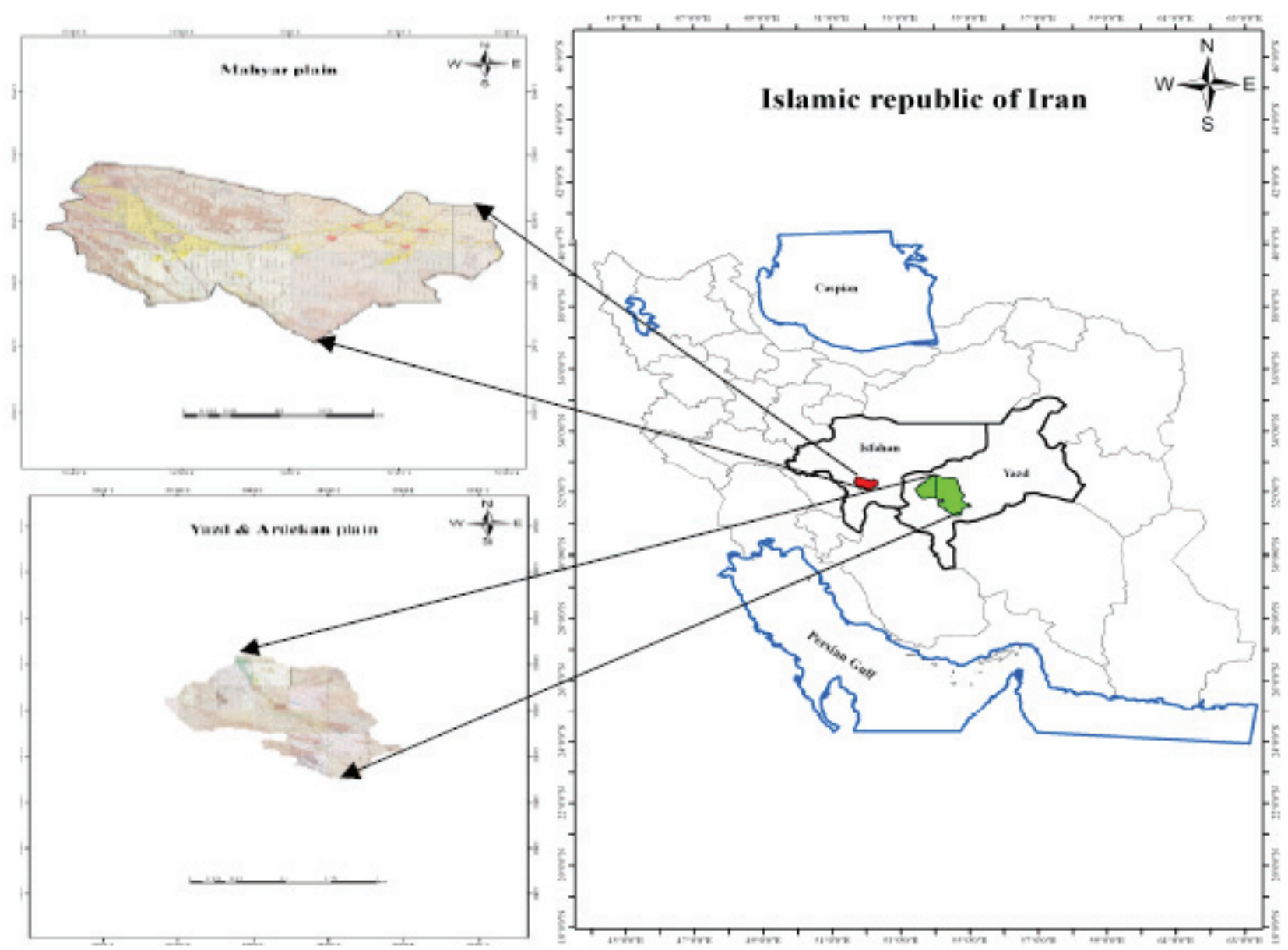

Fig. 1. Geography of the region of Yazd-Ardakan 


\section{The results}

We have gathered the necessary SAR information from Envisat satellite for the region of Mahyar and the data for the region of Yazd-Ardakan is gathered from European aerospace organization. The proposed study of this research first examines some important characteristics of the data such as normal baseline and Doppler to make sure that sufficient information are available on the data. Geomorphological analyses helps us investigate on the modifications that affect hydrographic basins, more specifically modifications because of active tectonics, and the quantitative descriptions of landforms. The study of geomorphic indices are normally used to appraise the influence of active faults on the hydrographic network. Table 1 shows details of the information.

Table 1

The summary of the necessary information of Baseline and Doppler for years of 2008 and 2009

\begin{tabular}{ll}
\hline Parameter & Value \\
\hline Normal Base line $(\mathrm{m})$ & 2074.449 \\
Critical Base line $(\mathrm{m})$ & 6529.615 \\
Ambiguity height $(\mathrm{m})$ & 30.869 \\
Range shift (pixels) & 151.983 \\
Azimuth shift (pixels) & -127.420 \\
Doppler centroid & 0.054 \\
Critical doppler & 2159.827 \\
\hline
\end{tabular}

As we can observe from the results of Table 1, all parameters such as Doppler centroid, Normal baseline, Critical baseline are statistically meaningful and we can analyze the results. The results indicate that the maximum subsidence in Yazd-Ardakan is about $16.8 \mathrm{~cm}$, which belongs to a Tile producer located 14 kilometers from the road of Yazd-Meibod. In addition, the maximum up lift is 6.7 to $10 \mathrm{~cm}$ North-East to east part of desert of Yazd-Ardakan. Fig 2 shows details of our investigation.
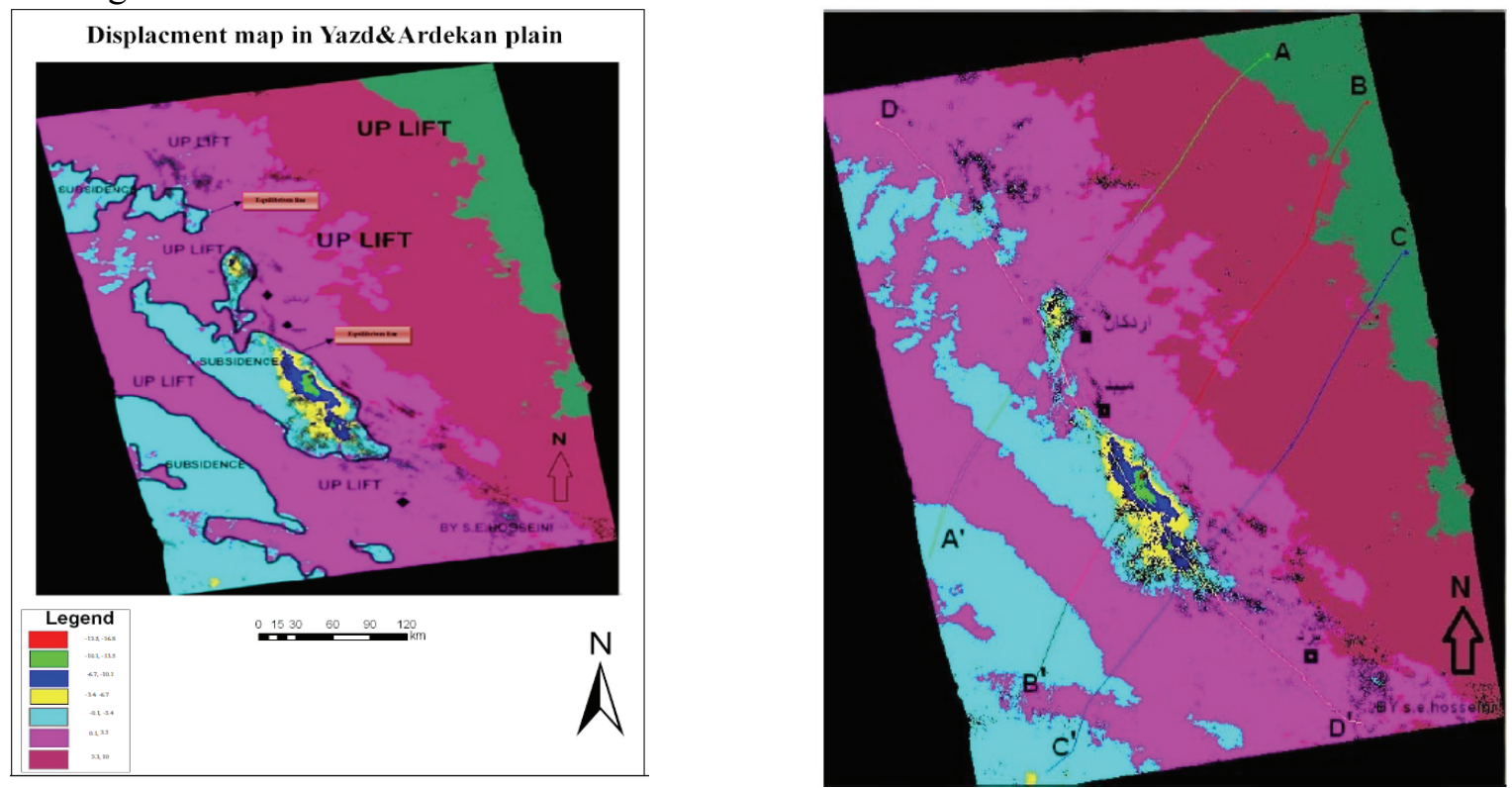

Fig. 2. Displacement map in Yazd-Ardakan plain

In order to show the subsidence, uplift and equilibrium line, we draw the Radar movement based on these changes in Fig 4. In this fig, we see the changes of each pixel based on the changes in subsidence and uplift. The vertical axis of Fig. 4 is in terms of meter and has two positive and 
negative sides, where the positive side is associated with uplift and the negative side is associated with subsidence.
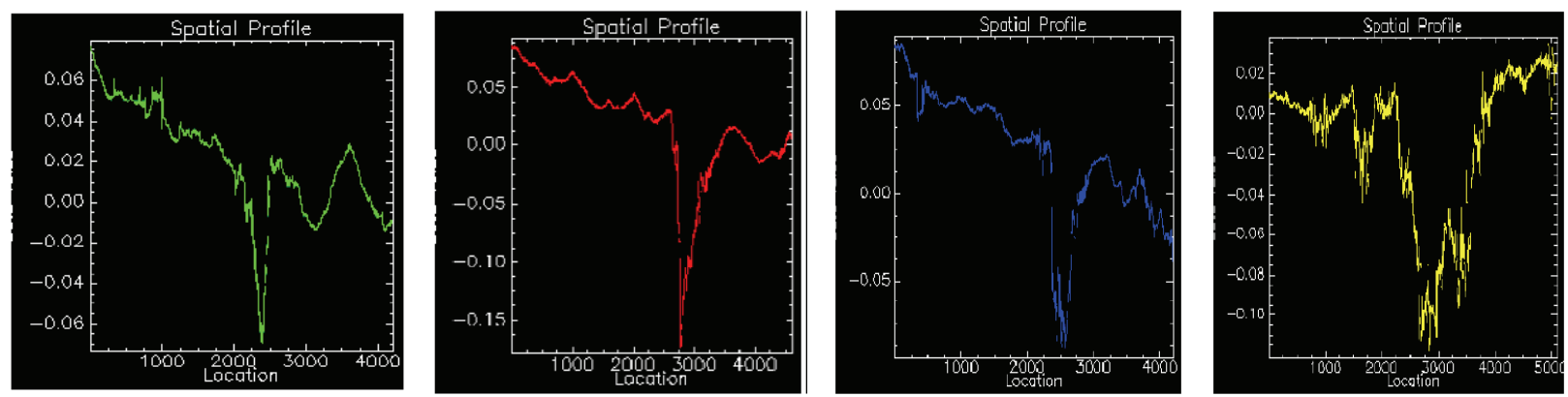

Fig. 4. A profile for Yazd-Ardakan

Similar investigations have been performed for Mahyar desert and the results indicate that the maximum up lift is about $35 \mathrm{~cm}$ in sought east of desert. Fig. 5 shows details of our suvery.
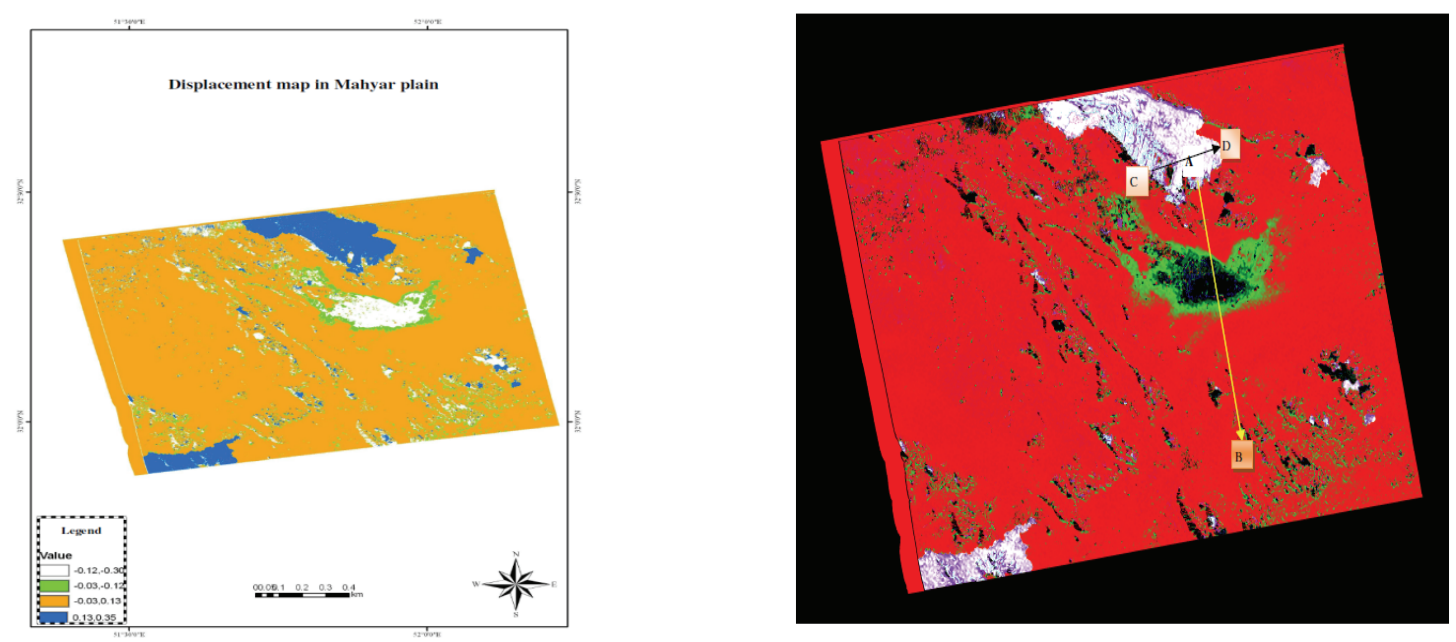

Fig. 5. Displacement map in Mahyar plain

As we explained earlier, the aim of this research is to support the theory of soft isostasy, which can be defined as the balanced coordinate movements between the plains and mountains surrounding them. Fig. 6 shows the profile of Mahyar region.
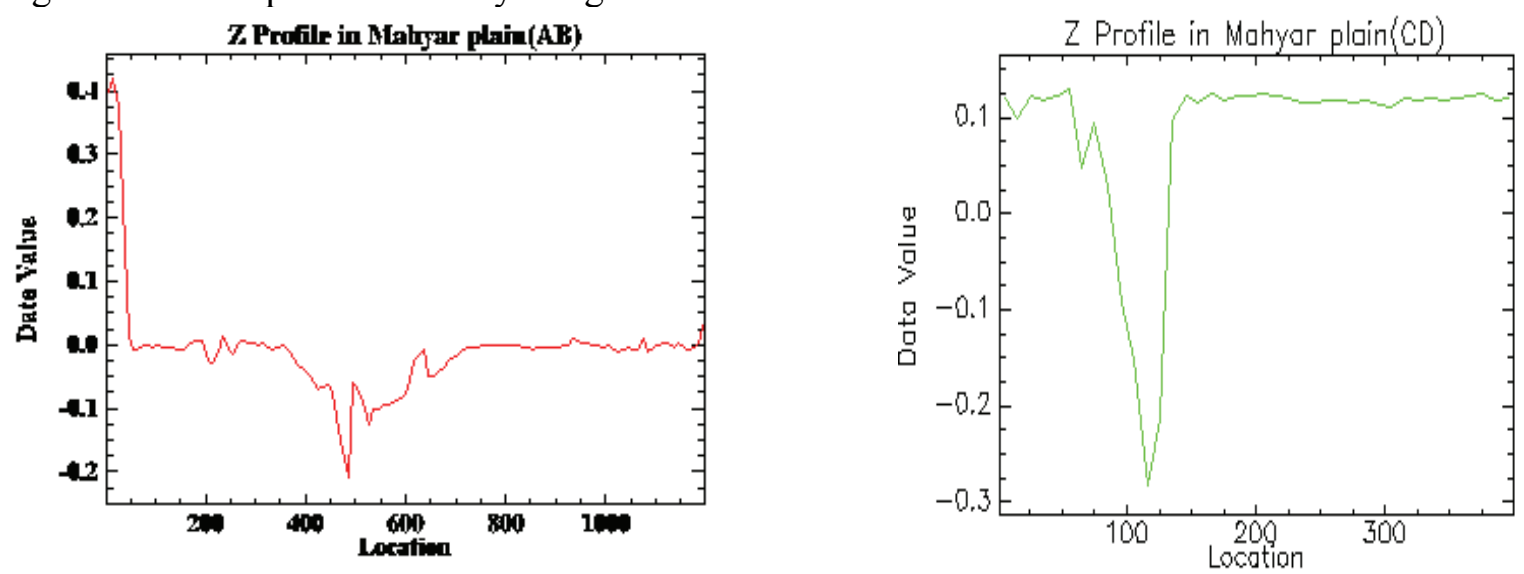

Fig. 6. A Profile for Mahyar region

These operations occur for years, which could cause the up lift and subsidence in the region. There is an equilibrium line in the region, where the movement becomes negligible around the line. A good perception of the nature of up lift and subsidence could help us prevent the bad effects on different constructions such as bridges, railways, etc. 


\section{Conclusion}

In this paper, we have presented an empirical investigation on two regions of Yazd-Ardakan and Mahyar plains to determine the up lift and subsidence in these regions. We have gathered some reliable data gathered by satellite and analyzed the results using SAR method. The results indicated that these two regions had some significant up lift and subsidence. Based on the preliminary results of this survey we would like to support the theory of soft isostasy defined as the balanced coordinate movements between the plains and mountains surrounding them. These operations occur for years, which could cause the up lift and subsidence in the region. We hope the results of this study could help understand the nature of up lift and subsidence, which could help us prevent any damages on different constructions such as bridges, railways, etc.

\section{Acknowledgment}

The authors would like to thank the anonymous referees for their constructive comments on earlier version of this work.

\section{References}

Burgmann, R., Rosen, P.A., \& Fielding, E.J. (2000). Synthetic aperture radar interferometry to measure Earth's surface topography and its deformation. Annual Review of Earth and Planetary Sciences, 28, 169-209.

Goldstein, R.M., Engelhardt, H., Kamb, B., \& Frolich, R. M. (1993). Satellite radar interferometry for monitoring ice sheet motion: application to an Antarctic ice streamy. Science, 262 (5139), 15251530 .

Guccione, M.J., Mueller, K., Champion, J., Shepherd, S., Carlson, S.D., Odhiambo, B., \& Tate, A. (2001). Stream response to repeated coseismic folding, Tiptonville dome, New Madrid seismic zone. Geomorphology, 43(3-4), 313-349.

Gutiérrez, F. (2004). Origin of the salt valleys in the Canyonlands section of the Colorado Plateau: Evaporite-dissolution collapse versus tectonic subsidence. Geomorphology, 57(3-4), 423-435.

Hanssen, R. F. (2001). Radar Interferometry: Data Interpretation and Error Analysis, Kluwer Academic, ISBN 9780792369455.

Heidari, M. Khanlari, G.R., Taleb Beydokhti, A.R., \& Momeni, A.A. (2011). The formation of cover collapse sinkholes in North of Hamedan, Iran. Geomorphology, 132(3-4), 76-86.

Jonathan D. Ph. (2001). Erosion, isostatic response, and the missing peneplains, Geomorphology 45 (2002) 225-241.

Keller, E.A., Duffy, M., Kennett, J.P., \& Hill, T. (2007).Tectonic geomorphology and hydrocarbon induced topography of the Mid-Channel Anticline, Santa Barbara Basin, California. Geomorphology, 89(3-4), 274-286.

Malik, J.N., \& Mohanty, C. (2002). Active tectonic influence on the evolution of drainage and landscape geomorphic signatures from frontal and hinter land areas along the North western Himalya, India. Journal of Asian Earth Sciences, 29, 604-618, 2007.

Massonnet, D., Rossi, M., Carmona, C., Adragna, F., Peltzer, G., Feigl, K., \& Rabaute, T. (1993). The displacement field of the Landers earthquake mapped by radar interferometry. Nature, 364(6433), 138-142.

Massonnet, D., Briole, P., \& Arnaud, A. (1995). Deflation of Mount Etna monitored by spaceborne radar interferometry. Nature, 375(6532), 567-570.

Massonnet, D. \& Feigl, K. L. (1998). Radar interferometry and its application to changes in the earth's surface. Reviews of Geophysics, 36 (4), 441-500.

Stecchi, F., Antonellini, M., \& Gabbianelli, G. (2009).Curvature analysis as a tool for subsidencerelated risk zones identification in the city of Tuzla (BiH). Geomorphology, 107(3-4), 316-325. 